\title{
CrystEngComm
}

PAPER

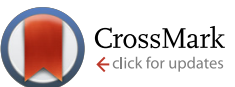

Cite this: CrystEngComm, 2015, 17, 4832

Received 21st April 2015,

Accepted 29th May 2015

DOI: $10.1039 / c 5 c e 00777 a$

www.rsc.org/crystengcomm

\section{Novel co-crystals of the nutraceutical sinapic acid $\dagger$}

\author{
A. S. Sinha, ${ }^{a}$ U. B. Rao Khandavilli, ${ }^{a}$ E. L. O'Connor, ${ }^{a}$ B. J. Deadman, ${ }^{a}$ A. R. Maguire ${ }^{\text {b }}$ \\ and S. E. Lawrence ${ }^{\star a}$
}

\begin{abstract}
Sinapic acid (SA) is a nutraceutical with known anti-oxidant, anti-microbial, anti-inflammatory, anti-cancer, and anti-anxiety properties. Novel co-crystals of SA were prepared with co-formers belonging to the category of GRAS [isonicotinic acid (INC), nicotinamide (NIA)], non-GRAS [4-pyridinecarbonitrile (PYC)], and active pharmaceutical ingredients (APIs) [6-propyl-2-thiouracil (PTU)] list of compounds. Structural study based on the X-ray crystal structures revealed the intermolecular hydrogen-bonded interactions and molecular packing. The crystal structure of sinapic acid shows the anticipated acid-acid homodimer along with discrete hydrogen bonds between the acid carbonyl and the phenolic moiety. The robust acid-acid homodimer appears to be very stable and is retained in the structures of two co-crystals (SA.NIA and SA.PYC). In these cases, co-crystallization occurs via intermolecular phenol $\mathrm{O}-\mathrm{H} \cdots \mathrm{N}_{\text {aromatic }}$ hydrogen bonds between the co-formers. In the SA.PTU.2MeCN co-crystal the acid-acid homodimer gives way to the anticipated acid-amide heterodimer, with the phenolic moiety of SA hydrogen-bonded to acetonitrile. Attempts at obtaining the desolvated co-crystal led to lattice breakdown, thus highlighting the importance of acetonitrile in the formation of the co-crystal. Among the co-crystals examined, SA.INC (5 weeks), SA.NIA ( 8 weeks) and SA.PYC (5 weeks) were found to be stable under accelerated humidity conditions $\left(40{ }^{\circ} \mathrm{C}, 75 \% \mathrm{RH}\right.$ ), whereas SA.PTU.2MeCN decomposed after one week into individual components due to solvent loss.
\end{abstract}

\section{Introduction}

'Crystal engineering', a term initially introduced by Pepinsky ${ }^{1}$ and developed by Schmidt, ${ }^{2}$ has been defined as: "the understanding of intermolecular interactions in the context of crystal packing and the utilisation of such understanding in the design of new solids with desired physical and chemical properties."3 The bulk properties of materials are directly affected by the assembly of molecules in the solid state, ${ }^{4}$ hence an important goal is the controlled assembly/ordering of molecules in the solid state.

Co-crystallization is an important part of crystal engineering and can be defined as the coming together of two or more neutral molecules in a crystalline lattice under ambient

\footnotetext{
${ }^{a}$ Department of Chemistry, Analytical and Biological Chemistry Research Facility, Synthesis and Solid State Pharmaceutical Centre, University College Cork, Cork, Ireland. E-mail: simon.lawrence@ucc.ie

${ }^{b}$ Department of Chemistry and School of Pharmacy, Analytical and Biological Chemistry Research Facility, Synthesis and Solid State Pharmaceutical Centre, University College Cork, Cork, Ireland

$\dagger$ Electronic supplementary information (ESI) available: Detailed list of coformers, IR, PXRD, DSC, TGA, stability data, and additional figures. CCDC 1060811-1060815. For ESI and crystallographic data in CIF or other electronic format see DOI: $10.1039 / \mathrm{c5ce00777a}$
}

conditions utilising intermolecular interactions such as hydrogen bonding, halogen bonding and $\pi-\pi$ bonding. ${ }^{5}$ It is a viable and effective method for improving the key bulk properties of a compound such as solubility, ${ }^{6}$ stability $^{7}$ and bioavailability. ${ }^{8}$ Pharmaceutical co-crystallization has gained particular attention within the past decade and is rapidly emerging as a valuable tool in the synthesis of new drugs with controlled physicochemical properties. ${ }^{9}$ Co-crystallization has been used in the agrochemical industry, ${ }^{10}$ and in the manufacture of explosives. ${ }^{11}$

The term nutraceutical was first introduced by Stephen Felice in the late eighties, ${ }^{12}$ and refers to compounds that are found in food or food products and can potentially aid in the treatment or even the prevention of diseases. ${ }^{13}$ Polyphenols are a common class of nutraceuticals found in fruits and vegetables which exhibit disease preventing capabilities and have been utilised as anti-oxidants, free radical scavengers and in cosmetic formulations. ${ }^{14,15}$ Although this valuable class of compounds possess obvious health benefits, some nutraceuticals are not physicochemically efficient due to poor stability, solubility and bioavailability. ${ }^{15}$ Thus, it is important to alter these key bulk properties of nutraceuticals in order to develop medicinally active forms that could prove valuable to the pharmaceutical industry. ${ }^{15}$ 
The choice of the co-former (co-crystal former) is important in pharmaceutical co-crystals and usually they are chosen from lists such as Generally Regarded As Safe (GRAS) ${ }^{16}$ and Everything Added to Food in the United States (EAFUS). ${ }^{17}$ An obvious choice for the class of compounds that can be used to extend the above lists of co-formers are nutraceuticals, which can act as good co-formers due to the variable co-crystal-forming functional groups present on their backbone. ${ }^{15}$ Also, their potential medicinal benefits along with their ready availability mean that nutraceuticals are attractive co-formers for pharmaceutical co-crystallization. ${ }^{15,18}$ Apart from the above, the three most important benefits of utilising nutraceuticals as co-formers for pharmaceutical co-crystallization are: (a) nutraceuticals that are bioactive can be co-administered with other bioactive drugs, thus targeting the synergy between the two components; (b) active pharmaceutical ingredients (APIs) with poor physicochemical properties can be co-crystallized with nutraceuticals in an attempt to synthesise new crystalline forms with improved physicochemical benefits; (c) anti-oxidant behavior of nutraceuticals can be used to impart stability to APIs that are prone to oxidation, or to reduce the incidence of diseases related to oxidative stress in the physiological state.

Sinapic acid is a widespread nutraceutical in the plant kingdom and is commonly found in fruits, vegetables, cereal grains, oilseed crops, and some spices and medicinal plants (Fig. 1). ${ }^{19}$ It can be classed as a phenolic acid and is known for its anti-oxidant, ${ }^{20}$ anti-microbial, ${ }^{21}$ anti-inflammatory, ${ }^{22}$ anti-cancer, ${ }^{23}$ and anti-anxiety activity. ${ }^{24}$ Indeed, it is a superior anti-oxidant than ferulic acid, ${ }^{25}$ which is already used as a natural anti-oxidant in foods, beverages, and cosmetics. ${ }^{26}$ 4-Vinylsyringol (Fig. 1), a decarboxylation product of sinapic acid, is a potent anti-oxidative and anti-mutagenic agent. ${ }^{27}$ Sinapine (sinapoyl choline) is an acetylcholinesterase inhibitor with biological applications in the treatment of various diseases (Fig. 1). ${ }^{28}$

Pharmacokinetic studies conducted on sinapic acid and its derivatives have highlighted the role of these phenolic acids in the human body. ${ }^{29-31}$ Sinapic acid is transported in blood due to its ability to bind with serum albumin via hydrogen bonds and hydrophobic interactions. ${ }^{29}$ In a study
Sinapic acid (SA)

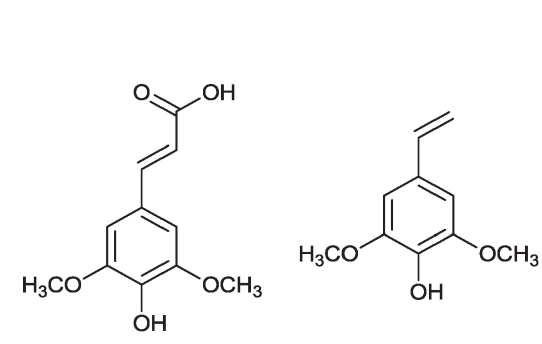

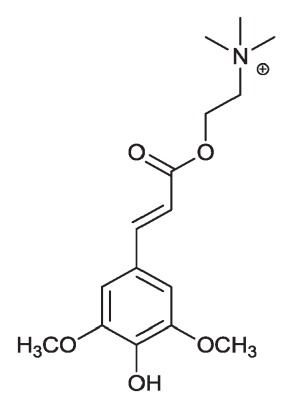

Sinapine (sinapoyl chloride)
Fig. 1 Structure of sinapic acid and its bioactive derivatives. on non-processed cereal, the maximum recorded sinapic acid level in the plasma was found to be $40 \mathrm{nM}$ with a bioavailability of $3 \% .^{30}$ Another study on cranberry juice intake by humans reported the plasma-sinapic acid level to be $1.5 \mu \mathrm{g}$ $\mathrm{mL}^{-1} \cdot{ }^{31}$ However, its poor solubility and, in turn, poor bioavailability means there are, to date, no pharmaceutically viable formulations of sinapic acid.

The solid-state structure of sinapic acid has not been described. Furthermore, there are no known co-crystals of sinapic acid, and the only reported crystal structure of SA is a methanol solvate. ${ }^{32}$ An understanding of the hydrogen bond behaviour of the functional groups on sinapic acid in the solid state is a key step in the selection of appropriate coformers towards the design of sinapic acid co-crystals. The solid-state chemistry of phenols and acids, the two hydrogenbonding functional groups present in sinapic acid, is well known. ${ }^{33,34}$ Acids usually form co-crystals via hydrogen bonding with functional groups including carboxylic acids, amides and pyridines. ${ }^{34}$ Phenols can act as both a hydrogen bond donor and an acceptor. Thus, they can hydrogen bond with acceptors such as pyridines and the oxygen atom of various carbonyl functional groups, as well as with donors including alcohols and other phenols. ${ }^{33}$ The calculated molecular electrostatic potentials (MEPs) of the carboxylic acid (+246 kJ $\left.\mathrm{mol}^{-1}\right)$ and the phenolic $\left(+218 \mathrm{~kJ} \mathrm{~mol}^{-1}\right)$ moieties on sinapic acid also highlight the hydrogen-bond donor potential of sinapic acid. ${ }^{15}$ Therefore, we anticipated that sinapic acid would form a range of intermolecular interactions such as

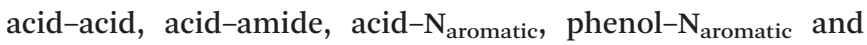
phenol-carbonyl hydrogen bonds, as illustrated in Fig. $2 .^{15}$ Furthermore, any unsatisfied donors or acceptors can potentially hydrogen bond with the five hydrogen-bond acceptors (carboxylic, phenolic and methoxy oxygen atoms) in sinapic acid that are also capable of a myriad of supramolecular interactions, thus giving rise to various possibilities for cocrystallization.

Accordingly, based on knowledge of hydrogen bond compatibility, calculated MEPs of sinapic acid and the expected motifs, we investigated the co-crystallization of sinapic acid with 21 co-formers containing three hydrogen-bond compatible

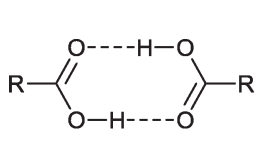

(a)

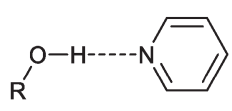

(d)

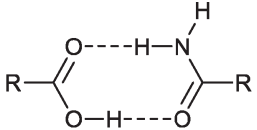

(b)

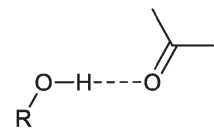

(e) (c)

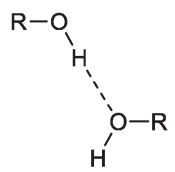

(f)

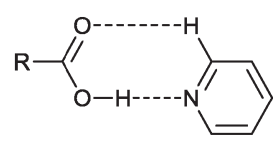

Fig. 2 Common hydrogen-bonding motifs involving acids (a-c) and phenols $(d-f)$. 
functional groups, namely carboxylic acids (Fig. 2a and e), amides (Fig. 2b and e), and pyridines (Fig. 2c and d) (detailed list provided in ESI $\dagger$ ). These co-formers were chosen because they possess relatively high aqueous solubilities. Additionally, we also investigated the co-crystallization of sinapic acid with four model APIs containing the carboxylic acid and secondary amide moieties (Fig. 2a-b, e), with the aim of exploring the possibility of co-administered drugs. The structural and stability data of sinapic acid and its co-crystals are reported herein.

\section{Experimental}

\section{Materials and methods}

The compounds utilised in this study were obtained from Sigma Aldrich and used as received. Solvents were obtained from commercial sources and distilled before use. Melting points were determined using an Electrothermal IA9100 melting point apparatus.

Screening involving mechanical grinding was employed with subsequent crystallization by slow evaporation from solution in all cases, even where grinding and IR indicated co-crystallization had not occurred.

Neat grinding. Screening was performed with a $1: 1$ ratio $(0.3 \mathrm{mmol})$ of the sinapic acid and co-formers. Mechanical grinding experiments were conducted in a Retsch MM400 Mixer mill, equipped with two stainless steel $5 \mathrm{~mL}$ grinding jars and one $2.5 \mathrm{~mm}$ stainless steel grinding ball per jar. The mill was operated at a rate of $30 \mathrm{~Hz}$ for $30 \mathrm{~min}$.

Infrared (IR) spectroscopy. Infrared spectra were recorded on a BRUKER TENSOR 37 FTIR spectrophotometer using a diamond ATR accessory over a range of 400-4000 $\mathrm{cm}^{-1}$.

Differential scanning calorimetry (DSC). Thermal analysis was recorded on a TI DSC Q1000 instrument. Samples (2-6 $\mathrm{mg}$ ) were crimped in nonhermetic aluminum pans and scanned from 30 to $250{ }^{\circ} \mathrm{C}$ at a heating rate of $5{ }^{\circ} \mathrm{C} \mathrm{min}^{-1}$ under a continuously purged dry nitrogen atmosphere.

Powder diffraction. All PXRD data were collected using a STOE STADI MP diffractometer with $\mathrm{Cu} \mathrm{K} \alpha$ radiation using a linear PSD over the $2 \theta$ range of $3.5-45.5^{\circ}$, with a step size equal to $1^{\circ}$ and step time equal to $30 \mathrm{~s}$. The samples were prepared as transmission foils and the data were viewed via STOE WinXPOW POWDAT.

High performance liquid chromatography (HPLC). The HPLC apparatus consisted of a 1260 Infinity Quaternary LC system (Agilent Technologies, Santa Clara, CA, USA) and ChemStation B.04.03.02 software (Agilent Technologies, Santa Clara, CA, USA) for data acquisition. A YMC-Pack ODS-A column (5 $\mu \mathrm{m}, 250 \mathrm{~mm} \times 4.6 \mathrm{~mm}$ i.d., YMC, Kyoto, Japan $)$ was used for chromatography. A binary mobile phase system of aqueous ammonium formate $\left(0.02 \mathrm{~mol} \mathrm{~L}^{-1}, \mathrm{pH} 4.0\right)$ and methanol (HPLC grade) was operated in a gradient from $20 \%$ to $60 \%$ methanol over $20 \mathrm{~min}$. The solvent composition was held at $60 \%$ methanol until 25 min before switching back to $20 \%$ over $1 \mathrm{~min}$ and equilibrating for $4 \mathrm{~min}$. The mobile

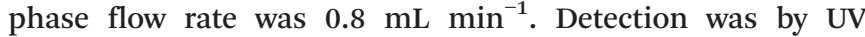
absorbance at 250, 280 and $320 \mathrm{~nm}$. All standard and sample solutions were prepared in methanol (HPLC grade). The injection volume was $25 \mu \mathrm{L}$.

\section{Solution crystallization}

Based on solubility considerations of both sinapic acid and the co-formers, four solvents (acetone, acetonitrile, ethanol and methanol) were selected for solution crystallization studies.

Sinapic acid (SA). Colourless needles suitable for single crystal X-ray diffraction were harvested after 3 days from acetone. The same form was also obtained from acetonitrile and ethanol. Melting point: $203-205{ }^{\circ} \mathrm{C}$; IR $v_{\max }\left(\mathrm{cm}^{-1}\right)$ : 3383 (br), 2838 (s), 2530 (br), 1658 (s), 1620 (s), 1593 (s), 1516 (s).

Sinapic acid:isonicotinic acid (SA-INC). Stoichiometric amounts of sinapic acid (67 $\mathrm{mg}, 0.3 \mathrm{mmol}$ ) and isonicotinic acid (37 mg, $0.3 \mathrm{mmol}$ ) were dissolved in each of the solvents. No suitable crystals for single crystal X-ray diffraction could be harvested even after repeated trials. The same form was obtained from all four solvents based on PXRD and IR analysis. Melting point: $220-224{ }^{\circ} \mathrm{C}$; IR $v_{\max }\left(\mathrm{cm}^{-1}\right): 3396$ (br), 3066 (s), 1697 (s), 1625 (s), 1603 (s), 1592 (s), 1518 (s); elemental analysis: (found: $\mathrm{C}, 58.11 ; \mathrm{H}, 4.88 ; \mathrm{N}, 4.05$. Calc. for $\mathrm{C}_{17} \mathrm{H}_{17} \mathrm{NO}_{7}$ : C, 58.79; $\mathrm{H}, 4.93$; N, 4.03\%).

Sinapic acid:nicotinamide (SA.NIA). Stoichiometric amounts of sinapic acid ( $67 \mathrm{mg}, 0.3 \mathrm{mmol}$ ) and nicotinamide ( $37 \mathrm{mg}, 0.3 \mathrm{mmol}$ ) were dissolved in each of the solvents. Yellow needles suitable for single crystal X-ray diffraction were harvested after 5 days from acetone. The same form was obtained from the other solvents. Melting point: $170-175{ }^{\circ} \mathrm{C}$; IR $v_{\max }\left(\mathrm{cm}^{-1}\right): 3385$ (s), 3203 (br), 2524 (br), 1664 (s), 1614 (s), 1578 (s), 1511 (s); elemental analysis: (found: C, 58.86; H, 5.13; N, 8.07. Calc. for $\mathrm{C}_{17} \mathrm{H}_{18} \mathrm{~N}_{2} \mathrm{O}_{6}: \mathrm{C}, 58.96 ; \mathrm{H}, 5.24 ; \mathrm{N}$, $8.09 \%)$.

Sinapic acid:4-pyridinecarbonitrile (SA.PYC). Stoichiometric amounts of sinapic acid $(67 \mathrm{mg}, 0.3 \mathrm{mmol})$ and 4-pyridinecarbonitrile ( $31 \mathrm{mg}, 0.3 \mathrm{mmol}$ ) were dissolved in each of the solvents. Yellow needles suitable for single crystal $\mathrm{X}$-ray diffraction were harvested after 4 days from methanol. The same form was obtained from the other solvents. Melting point: $142-144{ }^{\circ} \mathrm{C}$; IR $v_{\max }\left(\mathrm{cm}^{-1}\right)$ : $2840(\mathrm{br}), 2230(\mathrm{w})$, 1667 (s), 1619 (s), 1592 (s), 1511 (s); elemental analysis: (found: C, 61.97; $\mathrm{H}, 4.84 ; \mathrm{N}$, 8.03. Calc. for $\mathrm{C}_{17} \mathrm{H}_{16} \mathrm{~N}_{2} \mathrm{O}_{5}: \mathrm{C}$, 62.19; H, 4.91; N, 8.53\%).

Sinapic acid:6-propyl-2-thiouracil: $2 \mathrm{CH}_{3} \mathrm{CN}$ (SA·PTU·2MeCN). Stoichiometric amounts of sinapic acid $(67 \mathrm{mg}, 0.3 \mathrm{mmol})$ and 6-propyl-2-thiouracil ( $51 \mathrm{mg}, 0.3 \mathrm{mmol}$ ) were dissolved in each of the solvents. Colourless blocks of an acetonitrile solvate suitable for single crystal X-ray diffraction were harvested after 5 days from acetonitrile. Melting point: $168-172{ }^{\circ} \mathrm{C}$; IR $v_{\max }$ ( $\mathrm{cm}^{-1}$ ): 3298 (br), 3017 (br), 2934 (s), 2262 (w), 2253 (w), 1683 (s), 1633 (s), 1602 (s), 1573 (s), 1554 (s), 1514 (s); elemental analysis: (found: C, 54.30; H, 5.56; N, 7.37. Calc. for $\mathrm{C}_{22} \mathrm{H}_{28} \mathrm{~N}_{4} \mathrm{O}_{6} \mathrm{~S}$ : C, 55.45; H, 5.92; N, 11.76\%). The found 
elemental analysis matches the desolvated material (calc. for $\left.\mathrm{C}_{18} \mathrm{H}_{22} \mathrm{~N}_{2} \mathrm{O}_{6} \mathrm{~S}: \mathrm{C}, 54.81 ; \mathrm{H}, 5.62 ; \mathrm{N}, 7.10 \%\right)$.

\section{Crystallography}

Single crystal X-ray data were collected on a Bruker APEX II DUO diffractometer at room temperature or $100 \mathrm{~K}$ using graphite monochromatised Mo $\mathrm{K} \alpha(\lambda=0.7107 \AA)$ radiation or on a Bruker X2S at room temperature using graphite monochromatised Mo $\mathrm{K} \alpha(\lambda=0.7107 \AA)$ radiation. The structures were solved using direct methods and refined on $F^{2}$. Analysis was undertaken with the SHELX suite of programs ${ }^{35}$ and diagrams prepared with Mercury 3.3. ${ }^{36}$ All non-hydrogen atoms were located and refined with anisotropic thermal parameters. Hydrogen atoms were either placed in calculated positions or they were located and refined with isotropic thermal parameters. The detailed crystallographic data and structure refinement parameters for these compounds are summarised in Table 1.

\section{Physical form stability studies}

$200 \mathrm{mg}$ of each solid was taken in 8 dram vials and the physical stability was evaluated at $40 \pm 0.5{ }^{\circ} \mathrm{C}$ in $75 \%$ relative humidity. The vials of each co-crystal were subjected to the above accelerated stability conditions for 3 days and weekly intervals from 1 week to 8 weeks. PXRD and high performance liquid chromatography (HPLC) techniques were used to monitor the stability of the cocrystals.

\section{Results and discussion}

Co-crystallization of sinapic acid has been attempted with 21 different co-formers which belong to the GRAS ${ }^{16}$ and EAFUS lists, ${ }^{17}$ and non-GRAS compounds in order to develop novel crystalline materials of this nutraceutical. Of the 21 coformers examined, three successful co-crystals (SA.INC, SA.NIA and SA.PYC) were identified. Isonicotinic acid (INC) and nicotinamide (NIA) are GRAS compounds, and 4-pyridinecarbonitrile (PYC) is a non-GRAS co-former (Fig. 3).

Finally, four model APIs were also selected for cocrystallization with sinapic acid to investigate the potential of co-administered drugs. One successful co-crystal of SA with the API 6-propyl-2-thiouracil (PTU) was isolated as an acetonitrile solvate, and was fully characterised by solid-state techniques. PTU is an important drug used to treat hyperthyroidism including Graves' disease, ${ }^{37}$ and any new crystalline forms of this API have the potential to lead to new pharmaceutical formulations.

\section{Infrared (IR) spectroscopy}

The two main hydrogen bonding functional groups in sinapic acid are the phenolic and acid moieties. The characteristic IR carbonyl stretch $(\mathrm{C}=\mathrm{O})$ shows up in the region of 1650-1730 $\mathrm{cm}^{-1}$ depending on the nature of the carbonyl group (acid/ amide/aldehyde/ester). The carbonyl stretch of carboxylic acids generally appear between 1650-1700 $\mathrm{cm}^{-1}$, whereas phenols are known to absorb strongly in the region of 3400$3700 \mathrm{~cm}^{-1} .{ }^{38}$ Since the phenolic stretches are generally broad, and also coincide with the acid $\mathrm{O}-\mathrm{H}$ stretch of $\mathbf{S A}$, along with

Table 1 Crystallographic data for the compounds

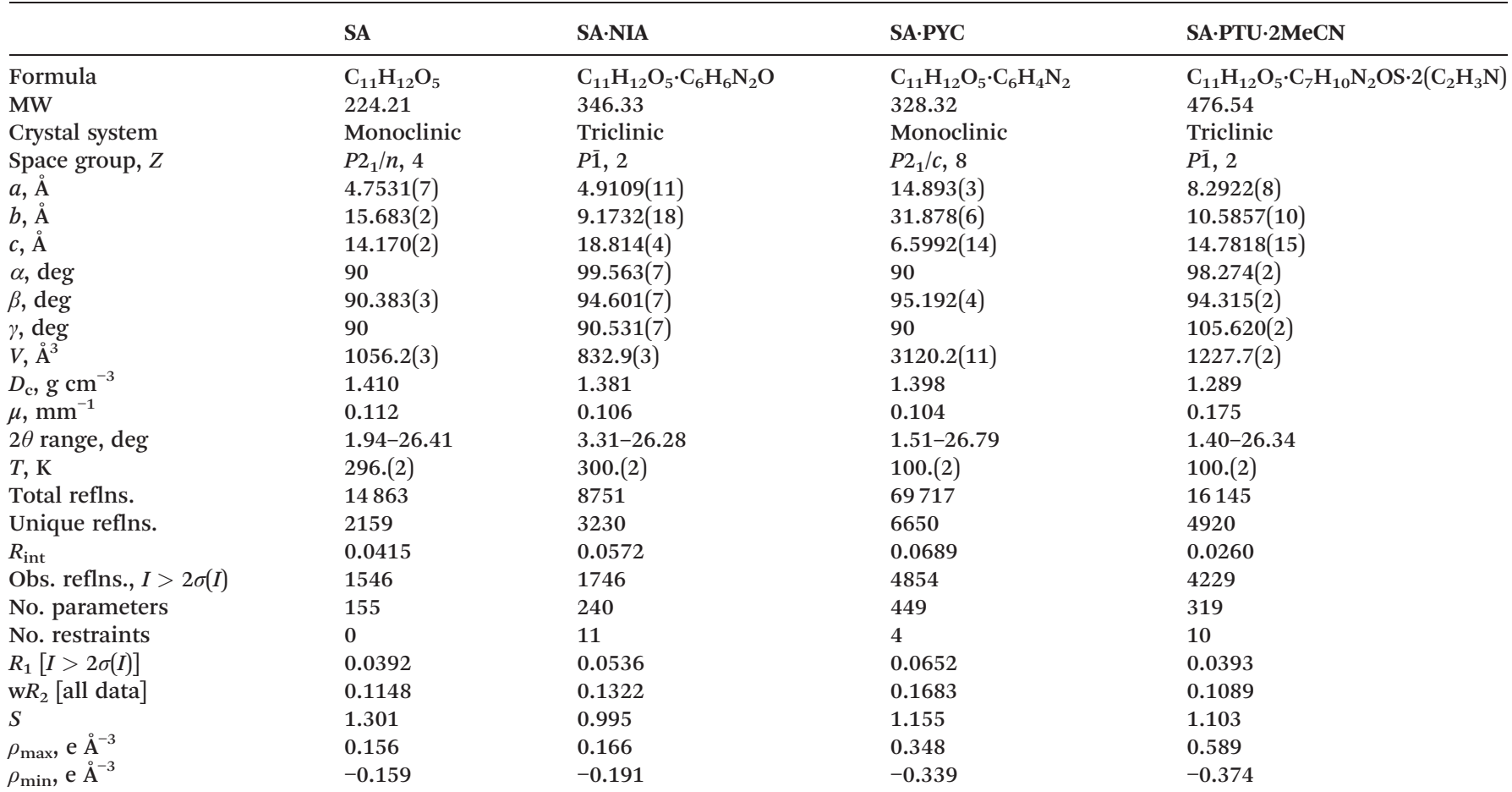


<smiles>O=C(O)c1ccncc1</smiles><smiles>NC(=O)c1cccnc1</smiles>

Isonicotinic acid (INC) Nicotinamide (NIA)<smiles>N#Cc1ccncc1</smiles><smiles>CCCc1cc(=O)[nH]c(=S)[nH]1</smiles>

4-Pyridinecarbonitrile (PYC)

6-Propyl-2-thiouracil (PTU)

Fig. 3 Structure of the four successful co-formers.

the co-former acid $\mathrm{O}-\mathrm{H}$ (INC) and amide $\mathrm{N}-\mathrm{H}$ (NIA) stretches, it is difficult to monitor these bands for any changes. Hence, the SA carbonyl stretch is a better indicator of hydrogen bonding in these co-crystals. The important carbonyl stretches in SA and its co-crystals are given in Table 2.

Co-crystal formation is indicated by blue shifts in the carbonyl stretch of sinapic acid, which is reflected in the longer $\mathrm{O}-\mathrm{H} \cdots \mathrm{O}=\mathrm{C}$ hydrogen bond distances in the cocrystals compared to sinapic acid. Blue-shifts of hydrogen bonds upon cocrystallization are not expected, however, computational investigations into this behaviour exist. ${ }^{39}$ In the case of SA.INC, the carbonyl stretch of SA is unidentifiable, but the overall shifts in the different bands in the IR spectrum are clearly indicative of the formation of a new solid phase. Another clear indicator of co-crystal formation is the presence of the $\mathrm{C} \equiv \mathrm{N}$ stretch due to the nitrile functional group at $2230 \mathrm{~cm}^{-1}$ for SA.PYC, 2253 and $2262 \mathrm{~cm}^{-1}$ for SA.PTU·2MeCN (Fig. 4).

\section{Structural analysis}

Sinapic acid by itself forms the anticipated acid-acid homodimer [Fig. 5 (blue)]. The phenol $\mathrm{OH}$ moieties are forming discrete hydrogen bonds with the oxygen atom of the carbonyl group [Fig. 5 (orange)], thus forming a twodimensional sheet. No polymorphs of sinapic acid were found using three solvents: acetone, acetonitrile and ethanol, while the methanol solvate obtained matched the previous report. $^{32}$

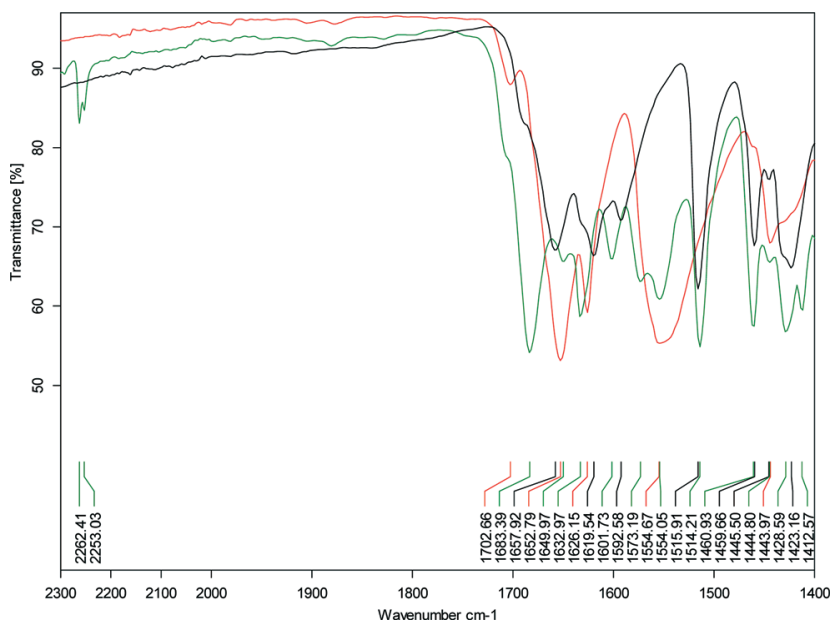

Fig. 4 Expanded view of the IR spectrum of SA.PTU.2MeCN showing the region from $1400-2300 \mathrm{~cm}^{-1}$ (black - SA; red - PTU; green SA.PTU.2MeCN).

A comparison of the structure of sinapic acid with the reported structure of its methanol solvate (WAMFOG) reveals that the acid-acid homodimer motif is common to both crystal structures [Fig. 6 (blue)], with the exception being the $\mathbf{R}_{4}^{4}(8)$ tetramer [Fig. 6 (orange)], which is formed by hydrogen bonds between two molecules of methanol and two phenolic moieties on adjacent sinapic acid molecules. ${ }^{32,40}$ This observation is in accordance with the data from the CSD on carboxylic acids, ${ }^{41}$ where in the absence of competing hydrogen bond acceptors, the carboxylic acid moiety will preferentially form the homodimer. Likewise, the phenolic substituent exhibits the common motifs associated with phenols, ${ }^{33}$ i.e. $\mathrm{O}-\mathrm{H} \cdots \mathrm{O}=\mathrm{C}$ acid heterosynthon in $\mathbf{S A}$, and phenol $\mathrm{O}-\mathrm{H} \cdots \mathrm{O}$ alcohol homosynthon in the methanol solvate.

The robust acid-acid homodimer in SA is retained in SA-NIA, with co-crystallization occurring via sinapic acid O$\mathrm{H} \cdots \mathrm{N}_{\text {aromatic }}$ hydrogen bonds (Fig. 7). Essentially, there are four different hydrogen bonds in the structure of SA-NIA: (a) acid-acid homodimer between two neighbouring sinapic acid molecules [Fig. 7 (blue)]; (b) discrete phenol $\mathrm{O}-\mathrm{H} \cdots \mathrm{N}_{\text {aromatic }}$ hydrogen bonds between SA and NIA responsible for extending the architecture [Fig. 7 (orange)]; (c) bifurcated amide $\mathrm{N}-\mathrm{H} \cdots \mathrm{O}$ methoxy/phenol hydrogen bonds which extends the structure in two dimensions [Fig. 7 (magenta)];

Table 2 Important IR stretches for the carbonyl group in sinapic acid and its co-crystals

\begin{tabular}{llll}
\hline Pure co-formers & & Co-crystals & \multicolumn{1}{c}{$v(\mathrm{C}=\mathrm{O})\left(\mathrm{cm}^{-1}\right)$} \\
\hline Compound & $v(\mathrm{C}=\mathrm{O})\left(\mathrm{cm}^{-1}\right)$ & Compound & - \\
SA & 1658 & - & $1697^{a}$ \\
INC & 1694 & SA.INC & $1664^{a}$ \\
NIA & 1674 & SA·NIA & 1667 \\
PYC & - & SA.PYC & $1683^{a}$
\end{tabular}

${ }^{a}$ Carbonyl stretches of the two co-formers are shifted and unidentifiable from each other. 


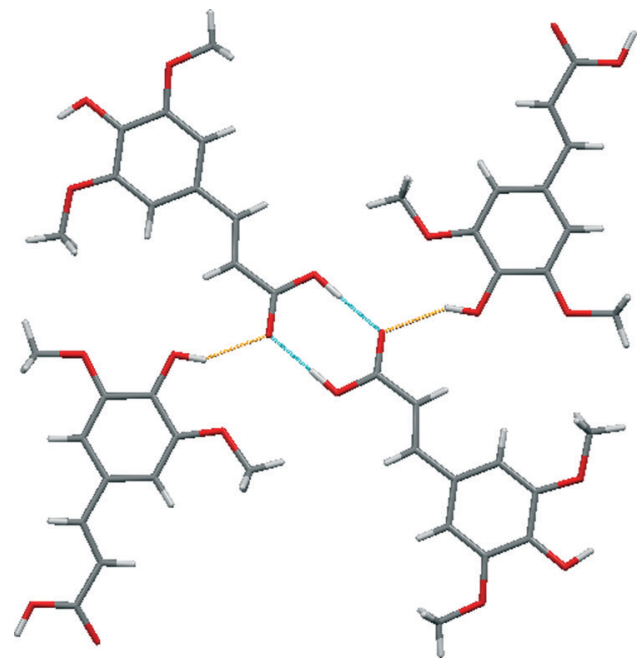

Fig. 5 A section of the crystal structure of SA highlighting the key hydrogen bonding interactions.

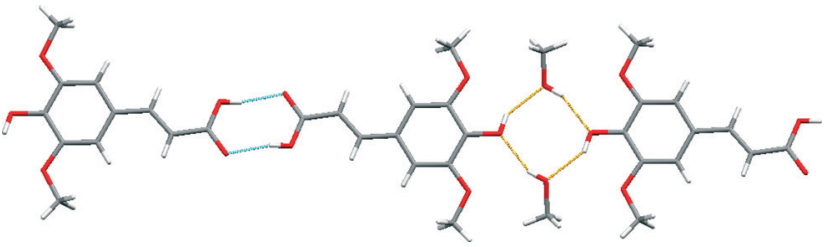

Fig. 6 The reported crystal structure of the methanol solvate of sinapic acid (WAMFOG). ${ }^{32}$

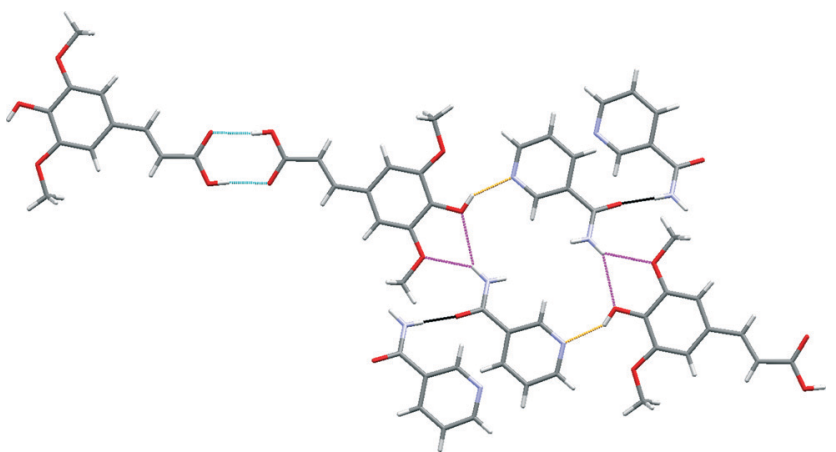

Fig. 7 A section of the crystal structure of SA.NIA highlighting the key hydrogen bonding interactions.

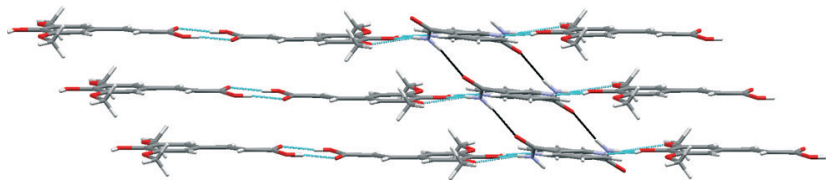

Fig. 8 Amide $\mathrm{N}-\mathrm{H} \cdots \mathrm{O}=\mathrm{C}$ amide $\mathrm{C}(4)$ chains (black) responsible for interlinking adjacent layers in the SA.NIA co-crystal.

and (d) anti-amide $\mathrm{N}-\mathrm{H} \cdots \mathrm{O}=\mathrm{C}$ amide $\mathrm{C}(4)$ chains responsible for interlinking adjacent layers [Fig. 7 (black) and 8]. Also, prevalent in the structure of this co-crystal is the $R_{4}^{4}(22)$

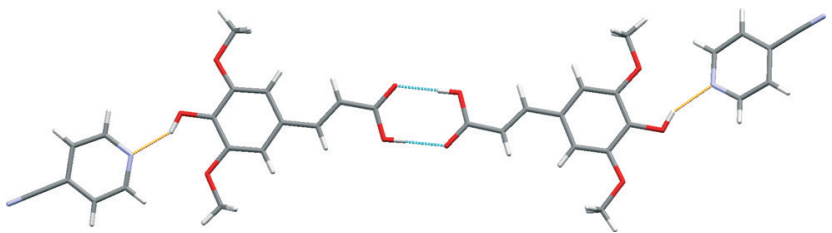

Fig. 9 A section of the crystal structure of SA.PYC highlighting the key hydrogen bonding interactions.

tetramer formed by two sinapic acid and two nicotinamide molecules.

The crystal structure of sinapic acid-4-pyridylcarbonitrile (SA.PYC) co-crystal displays the same two key hydrogen bonds as SA.NIA, i.e. the robust acid-acid homodimer [Fig. 9 (blue)] and the phenol $\mathrm{O}-\mathrm{H} \cdots \mathrm{N}_{\text {aromatic }}$ hydrogen bonds [Fig. 9 (orange)].

The carboxylic acid ( $\left.+246 \mathrm{~kJ} \mathrm{~mol}^{-1}\right)$ moiety on sinapic acid is a stronger hydrogen bond donor than the phenolic $(+218$ $\mathrm{kJ} \mathrm{mol}^{-1}$ ) moiety based on its molecular electrostatic potentials (MEPs). ${ }^{15}$ The presence of the electron donating methoxy groups in the ortho position on the aromatic ring are responsible for decreasing the calculated MEP values of the phenolic moiety. Thus, it is expected that the carboxylic acid moiety would form co-crystals utilizing the range of heteromeric hydrogen bonds available, such as acid-acid, acid-amide and acid- $\mathrm{N}_{\text {aromatic }} \cdot{ }^{34}$ Despite this, surprisingly, in the structures of the co-crystals SA.NIA and SA.PYC, the best donor (carboxylic acid) is not hydrogen-bonded to the best acceptor (pyridine nitrogen atom). ${ }^{42}$ The acid-acid homodimer is retained and co-crystallization occurs via phenol O$\mathrm{H} \cdots \mathrm{N}_{\text {aromatic }}$ hydrogen bonds. This has also been observed in the co-crystals of ferulic acid, ${ }^{43}$ a similar hydroxycinnamic acid, where the acid-acid dimer is retained, and no hydrogen bonds are observed between the best donor (carboxylic acid) and the best acceptor (pyridine nitrogen atom).

The crystal structure of SA.PTU.2MeCN displays three primary hydrogen-bonded interactions: (a) SA acid-amide (secondary) PTU $\mathbf{R}_{2}^{2}(8)$ heterodimer [Fig. 10 (blue)]; (b) PTU thioamide-thioamide $R_{2}^{2}(8)$ homodimer between two adjacent PTU molecules (homodimer is capped on both ends by the heterodimer) [Fig. 10 (magenta)]; and (c) SA phenol O-H $\cdots \mathrm{N}$ acetonitrile discrete hydrogen-bonds [Fig. 10 (orange)]. Furthermore, the hydrogen-bonded network is completed by

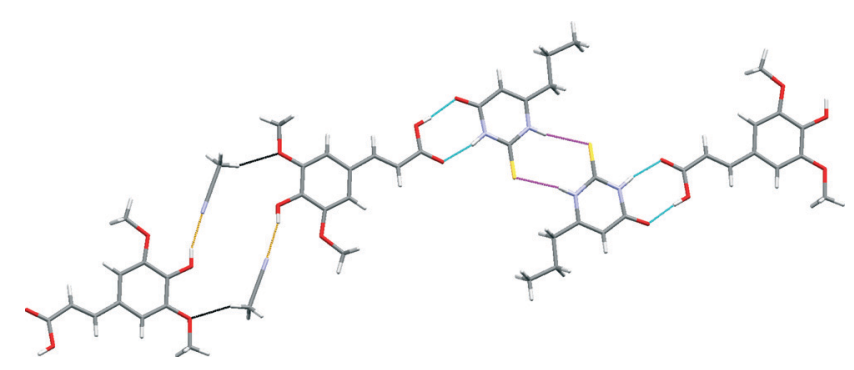

Fig. $10 \mathrm{~A}$ section of the crystal structure of SA.PTU.2MeCN highlighting the key hydrogen bonding interactions. 


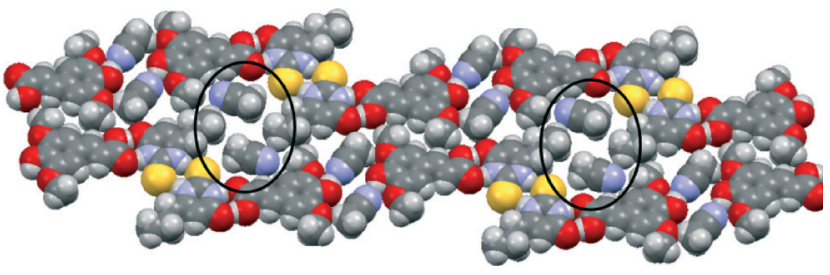

Fig. 11 Space-filling model of the crystal structure of SA.PTU.2MeCN highlighting the voids occupied by acetonitrile molecules.

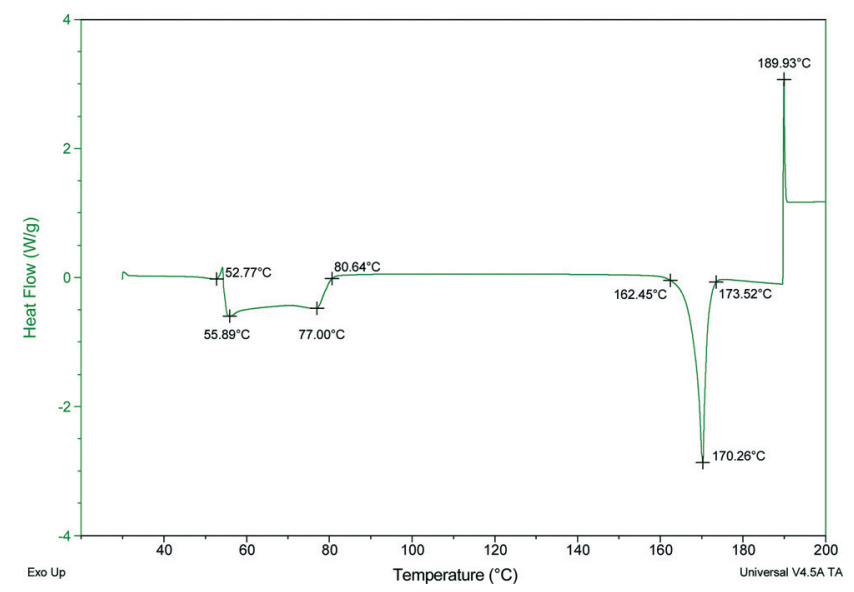

Fig. 12 DSC spectrum of SA.PTU.2MeCN showing the loss of the acetonitrile molecules.

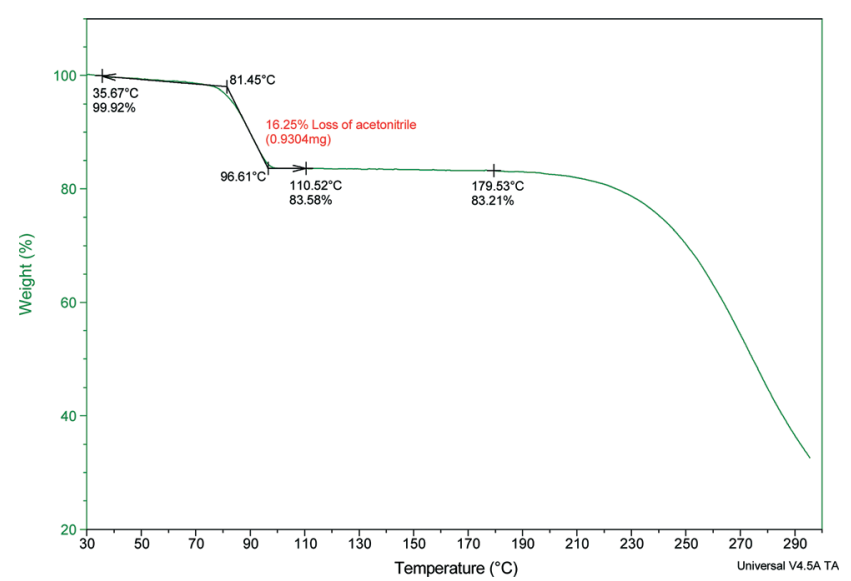

Fig. 13 TGA spectrum of SA.PTU.2MeCN showing the loss of the acetonitrile molecules.

structure-stabilising weak hydrogen bonds between the methyl hydrogen atom of acetonitrile and the methoxy oxygen atom of sinapic acid [Fig. 10 (black)] (C31-H31 $\cdots$ O12

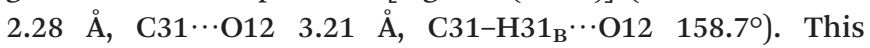
hydrogen-bonded network resembles 1-D zig-zag chains, and adjacent chains are close-packed to give an overall supramolecular architecture resembling 2-D sheets. The acetonitrile molecules occupy voids in the sheets with weak $\mathrm{C}-\mathrm{H} \cdots \mathrm{N}$ hydrogen bonds with adjacent molecules of SA and PTU (Fig. 11).

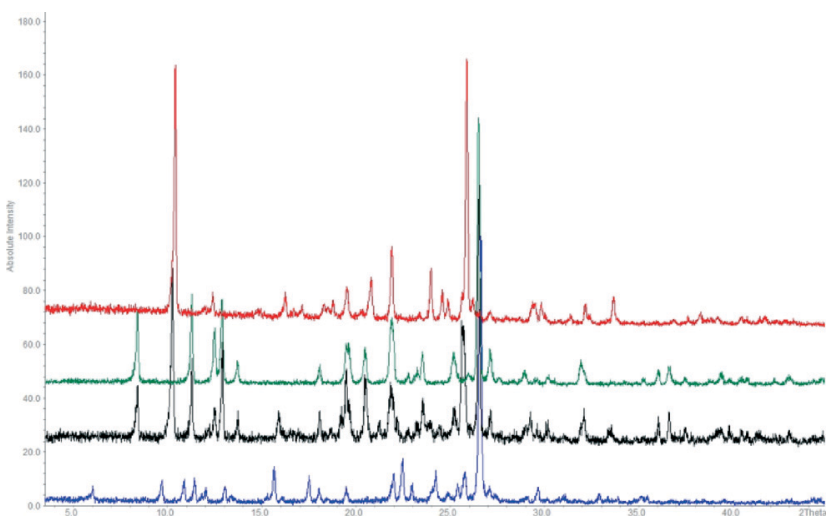

Fig. 14 PXRD pattern of SA.PTU.2MeCN (blue) compared with desolvated sample (black), sinapic acid (green), and 6-propyl-2-thiouracil (red).

A comparison of the structure of SA.PTU.2MeCN with the reported structure of PTU reveals that the thioamide-thioamide $\mathrm{R}_{2}^{2}(8)$ homodimer motif is common to both crystal structures. ${ }^{44}$ A notable difference is the secondary amideamide homodimer motif in PTU, which is unsurprisingly replaced by the preferred secondary amide-acid heterodimer in SA.PTU.2MeCN.

Acetonitrile molecules are required for the formation of this co-crystal since all other attempts to grow single crystals of a co-crystal of SA with PTU via solution crystallization proved unsuccessful. DSC analysis of the powder obtained from a grinding experiment of an equimolar mixture of SA and PTU reveals the formation of a material with the same melting point $\left(170{ }^{\circ} \mathrm{C}\right)$ as observed in the DSC analysis of SA.PTU.2MeCN (see ESI $\dagger$ ). Based on this knowledge, it may be theorised that for 6-propyl-2-thiouracil to co-crystallize with sinapic acid, the unsatisfied hydrogen-bond donor (phenolic moiety of SA) must be satisfied by a suitable hydrogen bond acceptor (acetonitrile nitrogen atom). Failing this, the two components would not come together in the crystal lattice. Hence, perhaps due to the size and shape of acetonitrile molecules, and the presence of a hydrogen bond acceptor in the form of the nitrile nitrogen atom, it was an ideal candidate to facilitate co-crystallization.

\section{Thermal stability}

The thermal stability and phase transitions of APIs are important in the study of their physicochemical properties. The DSC data for the co-crystals SA.INC, SA·NIA and SA·PYC show single endotherm peaks, which indicates that these cocrystals are thermally stable up to 224,175 and $143{ }^{\circ} \mathrm{C}$ respectively, with the melting point of the co-crystals lying inbetween that of the respective co-formers in all cases. Also, single endotherms in co-crystals SA.INC, SA.NIA and SA.PYC indicate that there is no decomposition prior to melting. Evolution of acetonitrile from SA.PTU.2MeCN occurred between 52-82 ${ }^{\circ} \mathrm{C}$ and the second endotherm for the melting point of 
Table 3 Stability of sinapic acid co-crystals under ICH conditions of $40^{\circ} \mathrm{C}$ and $75 \% \mathrm{RH}$

\begin{tabular}{|c|c|c|c|c|c|c|c|c|}
\hline SA.INC & $\sqrt{ }$ & $\sqrt{ }$ & $\sqrt{ }$ & $\sqrt{ }$ & $\sqrt{ }$ & $\mathrm{X}$ & $\mathrm{X}$ & $\mathrm{X}$ \\
\hline SA.PYC & $\sqrt{ }$ & $\sqrt{ }$ & $\sqrt{ }$ & $\sqrt{ }$ & $\sqrt{ }$ & $\mathrm{X}$ & $\mathrm{X}$ & $\mathrm{X}$ \\
\hline SA.PTU·2MeCN & $\sqrt{ }$ & $\mathrm{X}$ & $\mathrm{X}$ & $\mathrm{X}$ & $\mathrm{X}$ & $\mathrm{X}$ & $\mathrm{X}$ & $\mathrm{X}$ \\
\hline
\end{tabular}

the desolvated material was observed at $170{ }^{\circ} \mathrm{C}$ (Fig. 12). TGA data also support the equimolar stoichiometry in SA.PTU-2MeCN (Fig. 13). The powder X-ray diffraction pattern of the desolvated material clearly shows that the crystal lattice of SA.PTU.2MeCN falls apart, degrading to a physical mixture of the two components (Fig. 14). This further highlights the importance of the acetonitrile molecules in the formation of SA.PTU.2MeCN.

\section{Physical form stability}

An important characteristic of new pharmaceutical formulations that should be determined is the stability of the material with respect to changes in relative humidity and temperature. This knowledge aids in the storage and transportation of APIs without affecting drug activity. Sinapic acid is stable at accelerated $\mathrm{ICH}$ conditions of $40{ }^{\circ} \mathrm{C}$ and $75 \% \mathrm{RH}$ for up to 8 weeks as determined by PXRD and HPLC (Table 3). Three of the co-crystals, SA.INC, SA.NIA and SA.PYC, are stable under the same conditions for 5, 8 and 5 weeks, respectively, as determined by PXRD and HPLC, while SA.PTU.2MeCN is stable for only one week. This is indicated in the PXRD pattern by the appearance of peaks due to the co-former and loss of peaks associated with the co-crystal (see ESI $\dagger$ ). HPLC analyses of the dissolved co-crystals displayed only co-former peaks at 250, 280 and $320 \mathrm{~nm}$, which indicates that dissociation of the co-crystals is the major degradative pathway operating under these ICH conditions. We have also examined the equilibrium solubility of the co-crystals and did not observe any improvement in the solubility of sinapic acid in the co-crystals.

\section{Conclusions}

The co-crystallization of sinapic acid was attempted with a total of 25 different co-formers, 21 of which were simple model compounds (ten carboxylic acids, eight amides, three pyridines) and four were APIs. Four co-formers were successful and formed co-crystals which were isolated and characterised (one carboxylic acid, one amide, one pyridine and one API), and three co-crystals were structurally characterised by X-ray diffraction. The model compounds that were successful all had a pyridyl functional group present, although this did not guarantee success as three compounds containing this group (isonicotinamide, 4-hydroxypridine and 4,4'-bipyridine) did not form a co-crystal with sinapic acid. In the two model compounds that were structurally characterised, the sinapic acid forms acid-acid homodimers with the other co-formers joining these homodimers together via hydrogen bonding. It is only in the case of the acetonitrile solvate of sinapic acid with 6-propyl-2-thiouracil that acid-amide heterodimers between the two components are observed, and the presence of acetonitrile is necessary for the co-crystal to form. Thus, it appears that the sinapic acid homodimer is not easily replaced by acid-acid or acid-amide heterodimers. Participation of the phenol group is an important consideration when considering cocrystallization of sinapic acid, with phenol $\mathrm{O}-\mathrm{H} \cdots \mathrm{N}$ hydrogen bonds consistently displayed in all the co-crystals structurally characterised.

All co-crystals show good stability towards accelerated $\mathrm{ICH}$ humidity conditions with the exception of the solvate, which decomposes after one week with the loss of solvent. The cocrystal of sinapic acid with nicotinamide shows high stability and, thus, is an ideal candidate for exploring pharmaceutical formulations of sinapic acid.

\section{Acknowledgements}

This publication has emanated from research conducted with the financial support of Science Foundation Ireland under grant numbers 12/RC/2275 and 05/PICA/B802/EC07, and UCC 2013 Strategic Research Fund.

\section{Notes and references}

1 R. Pepinsky, Phys. Rev., 1955, 100, 971.

2 G. M. Schmidt, Pure Appl. Chem., 1971, 27, 647.

3 G. R. Desiraju, Crystal Engineering: The design of Organic Solids, Elsevier, Amsterdam, 1989.

4 C. B. Aakeröy, B. M. T. Scott, M. M. Smith, J. F. Urbina and J. Desper, Inorg. Chem., 2009, 48, 4052; L. Garzon-Tovar, A. Duarte-Ruiz and K. Wurst, Inorg. Chem. Commun., 2013, 32, 64; T. Mes, S. Cantekin, D. W. R. Balkenende, M. M. M. Frissen, M. A. J. Gillissen, B. F. M. De Waal, I. K. Voets, E. W. Meijer and A. R. A. Palmans, Chem. - Eur. J., 2013, 19, 8642.

5 C. B. Aakeröy and D. J. Salmon, CrystEngComm, 2005, 7, 439.

6 P. Sanphui, S. Tothadi, S. Ganguly and G. R. Desiraju, Mol. Pharmaceutics, 2013, 10, 4687; D. J. Good and N. RodríguezHornedo, Cryst. Growth Des., 2009, 5, 2252; C. B. Aakeröy, S. Forbes and J. Desper, J. Am. Chem. Soc., 2009, 131, 17048; K. Shiraki, N. Takata, R. Takano, Y. Hayashi and K. Terada, 
Pharmacol. Res., 2008, 25, 2581.

7 A. V. Trask, W. D. Samuel Motherwell and W. Jones, Int. J. Pharm., 2006, 320, 114; N. Rodríguez-Hornedo, S. J. Nehm and A. Jayasankar, Cocrystals: Design, Properties, and Formation Mechanisms, in Encyclopedia of Pharmaceutical Technology, ed. J. Swarbrick, Informa Healthcare, USA, 3rd edn, 2006; A. V. Trask, W. D. Samuel Motherwell and W. Jones, Cryst. Growth Des., 2005, 5, 1013.

8 M. L. Cheney, N. Shan, E. R. Healy, M. Hanna, L. Wojtas, M. J. Zaworotko, V. Sava, S. Song and J. R. Sanchez-Ramos, Cryst. Growth Des., 2010, 10, 394; M. B. Hickey, M. L. Peterson, L. A. Scoppettuolo, S. L. Morrisette, A. Vetter, H. Guzmán, J. F. Remenar, Z. Zhang, M. D. Tawa, S. Haley, M. J. Zaworotko and Ö. Almarsson, Eur. J. Pharm. Biopharm., 2007, 67, 112; D. P. McNamara, S. L. Childs, J. Giordano, A. Iarriccio, J. Cassidy, M. S. Shet, R. Mannion and A. Park, Pharmacol. Res., 2006, 23, 1888.

9 S. Aitipamula, R. Banerjee, A. K. Bansal, K. Biradha, M. L. Cheney, A. R. Choudhury, G. R. Desiraju, A. G. Dikundwar, R. Dubey, N. Duggirala, P. P. Ghogale, S. Ghosh, P. K. Goswami, N. R. Goud, R. R. K. R. Jetti, P. Karpinski, P. Kaushik, D. Kumar, V. Kumar, B. Moulton, A. Mukherjee, G. Mukherjee, A. S. Myerson, V. Puri, A. Ramanan, T. Rajamannar, C. M. Reddy, N. Rodriguez-Hornedo, R. D. Rogers, T. N. G. Row, P. Sanphui, N. Shan, G. Shete, A. Singh, C. C. Sun, J. Swift, R. Thaimattam, T. S. Thakur, R. K. Thaper, S. P. Thomas, S. Tothadi, V. R. Vangala, N. Variankaval, P. Vishweshwar, D. R. Weyna and M. J. Zaworotko, Cryst. Growth Des., 2012, 12, 2147; N. Blagden, S. J. Coles and D. J. Berry, CrystEngComm, 2014, 16, 5753; J. W. Steed, Trends Pharmacol. Sci., 2013, 34, 185; H. G. Brittain, J. Pharmacol. Sci., 2013, 102, 311.

10 E. Nauha, Crystalline forms of selected agrochemical actives: design and synthesis of co-crystals, Department of Chemistry, University of Jyväskylä, Research report No. 151, 2012.

11 O. Bolton, L. R. Simke, P. F. Pagoria and A. J. Matzger, Cryst. Growth Des., 2012, 12, 4311; K. B. Landenberger, O. Bolton and A. J. Matzger, Angew. Chem., Int. Ed., 2013, 52, 6468; J. Evers, I. Gospodinov, M. Joas, T. M. Klapötke and J. Stierstorfer, Inorg. Chem., 2014, 53, 11749.

12 V. Brower, Nat. Biotechnol., 1998, 16, 728.

13 S. H. Zeisel, Science, 1999, 285, 1853; E. K. Kalra, AAPS PharmSci, 2003, 5, e25.

14 A. Munin and F. Edwards-Lévy, Pharmaceutics, 2011, 3, 793; M. Massaro, E. Scoditti, M. A. Carluccio and R. De Caterina, Cardiovasc. Ther., 2010, 28, e13; M. Pandey, R. K. Verma and S. A. Saraf, Asian J. Pharm. Clin. Res., 2010, 3, 11.

15 A. S. Sinha, A. R. Maguire and S. E. Lawrence, Cryst. Growth Des., 2015, 15, 984.

16 Generally Regarded as Safe: http://www.cfsan.fda.gov/ rdb/ opagras.html and http://www.cfsan.fda.gov/ dms.grasguid. html.

17 Everything Added to Food in the United States: http://www. usc.es/caa/EdulcWeb/EAFUS.pdf.

18 B. S. Sekhon, RGUHS J. Pharm. Sci., 2012, 2, 16.
19 N. Nićiforović and H. Abramovič, Compr. Rev. Food Sci. Food Saf., 2014, 13, 34; C. Chen, Sinapic Acid and Its Derivatives as Medicine in Oxidative Stress-Induced Diseases and Aging, Oxid. Med. Cell. Longevity, 706190, in press.

20 F. Natella, M. Nardini, M. Di Felice and C. Scaccini, J. Agric. Food Chem., 1999, 47, 1453; H. Kikuzaki, M. Hisamoto, K. Hirose, K. Akiyama and H. Taniguchi, J. Agric. Food Chem., 2002, 50, 2161; Y. Zou, A. R. Kim, J. E. Kim, J. S. Choi and H. Y. Chung, J. Agric. Food Chem., 2002, 50, 5884.

21 S. Tesaki, S. Tanabe, H. Ono, E. Fukushi, J. Kawabata and M. Watanabe, Biosci., Biotechnol., Biochem., 1998, 62, 998; C. E. Maddox, L. M. Laur and L. Tian, Curr. Microbiol., 2010, 60, 53; C. Engels, A. Schieber and M. G. Gänzle, Eur. Food Res. Technol., 2012, 234, 535.

22 K.-J. Yun, D.-J. Koh, S.-H. Kim, S. J. Park, J. H. Ryu, D.-G. Kim, J.-Y. Lee and K.-T. Lee, J. Agric. Food Chem., 2008, 56, 10265.

23 E. A. Hudson, P. A. Dinh, T. Kokubun, M. S. Simmonds and A. Gescher, Cancer Epidemiol., Biomarkers Prev., 2000, 9, 1163.

24 B. H. Yoon, J. W. Jung, J.-J. Lee, Y.-W. Cho, C.-G. Jang, C. Jin, T. H. Oh and J. H. Ryu, Life Sci., 2007, 81, 234.

25 M.-E. Cuvelier, H. Richard and C. Berset, Biosci., Biotechnol., Biochem., 1992, 56, 324.

26 R. J. Robbins, J. Agric. Food Chem., 2003, 51, 2866.

27 H. Kuwahara, A. Kanazawa, D. Wakamatu, S. Morimura, K. Kida, T. Akaike and H. Maeda, J. Agric. Food Chem., 2004, 52, 4380.

28 L. He, H. T. Li, S. W. Guo, L. F. Liu, J. B. Qiu, F. Li and B. C. Cai, Zhongguo Zhongyao Zazhi, 2008, 33, 813; F. Ferreres, F. Fernandes, C. Sousa, P. Valentão, J. A. Pereira and P. B. Andrade, J. Agric. Food Chem., 2009, 57, 8884.

29 O. G. Bountagkidou, S. A. Ordoudi and M. Z. Tsimidou, Food Res. Int., 2010, 43, 2014; L. Trnková, I. Boušová, L. Ryšánková, P. Vrabcová and J. Dršata, Proc. ECOpole, 2009, 3, 27.

30 S. M. Kern, R. N. Bennett, F. A. Mellon, P. A. Kroon and M.-T. Garcia-Conesa, J. Agric. Food Chem., 2003, 51, 6050.

31 K. Zhang and Y. Zuo, J. Agric. Food Chem., 2004, 52, 222.

32 H. Qian and W. Huang, J. Mol. Struct., 2005, 743, 191.

33 C. Laurence, $M$. Berthelot and J. Graton, Hydrogen-Bonded Complexes of Phenols, in Phenols, ed. Z. Rappoport, John Wiley \& Sons, Ltd., Chichester, U.K., 2003; O. Ermer and A. Eling, J. Chem. Soc., Perkin Trans. 2, 1994, 925; F. G. Bordwell, R. J. McCallum and W. N. Olmstead, J. Org. Chem., 1984, 49, 1424.

34 D. Hadzi and S. Detoni, Hydrogen bonding in carboxylic acids and derivatives, in Acid Derivatives, ed. S. Patai, John Wiley \& Sons, Ltd., Chichester, U.K., 1979, vol. 1; W. C. Hamilton and J. A. Ibers, Hydrogen Bonding in Solids, ed. W. A. Benjamin, New York, 1968.

35 G. M. Sheldrick, Acta Cryst., 2008, A64, 112.

36 C. F. Macrae, I. J. Bruno, J. A. Chisholm, P. R. Edgington, P. McCabe, E. Pidcock, L. Rodriguez-Monge, R. Taylor, J. van de Streek and P. A. Wood, J. Appl. Cryst., 2008, 41, 466. 
37 H. Nakamura, J. Y. Noh, K. Itoh, S. Fukata, A. Miyauchi and N. Hamada, J. Clin. Endocrinol. Metab., 2007, 92, 2157.

38 K. Nakamoto, Y. Morimoto and A. E. Martell, J. Phys. Chem., 1962, 66, 346; G. Socrates, Infrared and Raman charateristic group frequencies; tables and charts, John Wiley and Sons, 2004.

39 S. Inagaki, H. Murai and T. Takeuchi, Phys. Chem. Chem. Phys., 2012, 14, 2008; J. Joseph and E. D. Jemmis, J. Am. Chem. Soc., 2007, 129, 4620; X. Li, L. Liu and H. B. Schlegel, J. Am. Chem. Soc., 2002, 124, 9639.

40 For a description of graph set notation for classifying hydrogen-bonding patterns, see: J. Bernstein, R. E. Davis, L. Shimoni and N.-L. Chang, Angew. Chem., Int. Ed.
Engl., 1995, 34, 1555; M. C. Etter, Acc. Chem. Res., 1990, 23, 120.

41 T. R. Shattock, K. K. Arora, P. Vishweshwar and M. J. Zaworotko, Cryst. Growth Des., 2008, 8, 4533.

42 For a description of best donor - best acceptor theory for hydrogen bonding, see: M. C. Etter and G. M. Frankenbach, Chem. Mater., 1989, 1, 10; M. C. Etter, J. Phys. Chem., 1991, 95, 4601.

43 B. Swapna, D. Maddileti and A. Nangia, Cryst. Growth Des., 2014, 14, 5991; Z. Tan, E. Zhu, L. Luo, Z. Lin and R. Yan, Acta Crystallogr., Sect. E: Struct. Rep. Online, 2011, 67, 0424.

44 F. F. Ferreira, A. C. Trindade, S. G. Antonio and C. O. PaivaSantos, CrystEngComm, 2011, 13, 5474. 